\title{
PNL2, a New Monoclonal Antibody Directed against a Fixative-Resistant Melanocyte Antigen
}

Philippe Rochaix, M.D., Ph.D., Magali Lacroix-Triki, M.D., Laurence Lamant, M.D., Ph.D., Carole Pichereaux, Severine Valmary, M.D., Elena Puente, Ph.D., Talal Al Saati, M.D., Bernard Monsarrat, Ph.D., Christiane Susini, Ph.D., Louis Buscail, M.D., Ph.D., Georges Delsol, M.D., Jean-Jacques Voigt, M.D.

Laboratoire d'anatomie et cytologie pathologiques, Institut Claudius Regaud (PR, ML-T, J-JV); Centre de Physiopathologie de Toulouse-Purpan (INSERM U563) et Laboratoire d'anatomie et cytologie pathologiques CHU Purpan Toulouse (LL, SV, TAS, GD); INSERM U 531-Institut Louis Bugnard-IFR-31 (PR, EP, CS, LB); and Institut de Pharmacologie et de Biologie Structurale CNRS (CP, BM), Toulouse, France

We report the production of a new monoclonal antibody, PNL2, directed against a fixative resistant melanocyte antigen. The analysis of PNL2 immunostaining on a broad range of normal or malignant human tissues and on various melanocytic lesions revealed its high specificity. PNL2 gave a strong cytoplasmic staining of skin and oral mucosae melanocytes, and staining of granulocytes when used at high concentration. PNL2 stained all intraepidermal nevi irrespective of their histologic type, but common intradermal nevi and the dermal component of compound nevi were largely non-reactive as only scattered nevus cells in the papillary dermis were labeled. PNL2 labeled more than $70 \%$ of the neoplastic cells in all primary melanomas irrespective of their histologic type. However, PNL2 did not label desmoplastic melanomas. All metastatic melanomas were also stained but the percentage of labeled cells was occasionally lower than the primary tumor. PNL2, as anti-Melan A and HMB-45 antibodies, stained most of the clear cell sarcoma cells, and a few cells in angiomyolipomas and lymphangioleiomyomatosis. None of the other nonmelanocytic lesions tested were labeled. Proteomic approaches showed that the immunoaffinity purified PNL2-binding complexes isolated from melanoma cell lines comprise at least TAP1, Clathrin 17 and prealbumin proteins, but not the gp100 recog-

Copyright (C) 2003 by The United States and Canadian Academy of Pathology, Inc.

VOL. 16, NO. 5, P. 481, 2003 Printed in the U.S.A.

Date of acceptance: January 8, 2003.

Aided in part by grants from the Association pour la Recherche sur le Cancer (ARC-"réseau ARECA"-"protéomique et cancer") and from

"Groupe de Recherche" Institut Claudius REGAUD.

Address reprint requests to: Rochaix Philippe, M.D., Ph.D., Laboratoire d'anatomie et cytologie pathologiques, Institut Claudius Regaud, 20-24 rue du pont Saint Pierre, 31052 Toulouse, France; fax: 335614246 02; e-mail: rochaix@icr.fnclcc.fr.

DOI: 10.1097/01.MP.0000067686.34489.50 nized by HMB-45. In conclusion, this new monoclonal antibody, PNL2, is directed against a new fixative resistant melanocyte associated antigen. This antigen is chemically resistant and thus allows immunostaining after melanin bleaching or decalcification. We also demonstrate that it is different from Melan A and from gp100, even if PNL2 and HMB-45 staining patterns are sometimes similar.

KEY WORDS: Clathrin 17, Melanoma, Monoclonal antibody, Immunohistochemistry, Pre albumin, Proteomic, TAP1.

Mod Pathol 2003;16(5):481-490

Melanocyte proliferation often constitutes a diagnostic problem in surgical pathology. The differential diagnosis between benign nevi and malignant melanomas is sometimes difficult and malignant melanomas may mimic other neoplasms such as undifferentiated carcinoma, sarcoma or large cell lymphoma (1). Furthermore, melanocyte-specific antigens expression is of diagnostic value in some soft tissue lesions such as clear cell sarcoma, angiomyolipoma, and lymphangiomyomatosis (2). The increasing number of monoclonal antibodies (Mab) directed against formalin resistant melanoma associated antigens such as gp100 (HMB-45 Mab), Melan A (A103 Mab), CD63 (NKI/C-3 Mab), MAGE 1, MAGE 3, or tyrosinase (T311 Mab) has provided useful diagnostic tools (3-16). However, some melanocytic lesions lack most of these antigens, and non-melanocytic lesions may express melanocyte-related antigens (17-19). The use of a broad range of antibodies is therefore needed for definitive identification.

Furthermore, the increasing interest in sentinel lymph node examination and the development of ultrarapid immunostaining protocols for frozen 
sections emphasize the need of highly sensitive and specific anti-melanocyte antibodies.

At least, antigen-targeted approach in melanoma therapy highlights the interest of new melanoma specific proteins (20-32).

We herein report the production of a new monoclonal antibody, named PNL2, directed against a fixative resistant melanocyte associated antigen. This antibody can be used on routinely processed paraffin sections. A detailed analysis of the reactivity of PNL2 on a broad range of normal or malignant human tissues and on various melanocytic lesions is provided below to reveal its high specificity. The results are compared with those obtained using HMB-45 and anti-Melan A (clone A103) antibodies. These findings point to potential applications of the PNL2 Mab in the immunostaining of melanomas and basic research.

\section{MATERIALS AND METHODS}

\section{Production of PNL2 Mab}

PNL2 Mab was generated using BALB/C mice immunized by intraperitoneal injections of a recombinant protein corresponding to the C-terminal part of the sub-type 2 of human somatostatin receptor (SST2) coupled with glutathione S-transferase. The non-immunoglobulinproducing myeloma cell line P3 × 63 Ag8-653 was used as a fusion partner. Fusions were performed using standard techniques $(33,34)$. Supernatants were tested for antibody-binding activity by ELISA and by indirect immunoperoxidase method on frozen sections of human pancreas and tonsil. Isotype characterization was performed using IsoStrip mouse Mab isotyping kit according to manufacturer's protocol.

\section{Immunostaining}

Immunohistochemistry was performed on $4-\mu \mathrm{m}$ routinely processed paraffin sections using a Techmate Horizon slide processor. A prior antigen retrieval based on microwave heating $(10 \mathrm{~mm}$ citrate buffer, $\mathrm{pH}$ 6) was needed for anti-Melan A (clone A103, DAKO, Glostrup, Denmark) and PNL2 antibodies. An enzymatic digestion was performed using Proteinase $\mathrm{K}$ according to the manufacturer's protocol (ChemMate, DAKO) before HMB-45 (DAKO) immunostaining. Antibody binding was revealed using a streptavidin-biotin complex reagent (StrepABComplex/HRP Duet, DAKO) on human samples and using the "Animal Research Kit" ARK (DAKO) on mouse samples according to manufacturer's protocol. PNL2 supernatant, anti-Melan A and HMB-45 were used respectively in 1/2,1/40 and 1/75 dilution. Negative controls were performed for each sample using the supernatant of the cell line P3 $\times 63$ Ag8-653 as the primary antibody.

All the tissue samples were fixed in ethanol based Bouin's fluid or in $4 \%$ formalin and were wax embedded. They consisted of a wide variety of normal human tissues (Table 1), 96 cases of melanocytic neoplasms (Table 2) including 47 benign lesions and 49 cases of melanoma (the latter included 32 primary cutaneous melanomas of different histologic types and 17 metastatic melanomas), 208 cases of non-melanocytic tumors of different categories (Table 3 ), and a panel of various tissues from white (Balb/c), black (C57/Bl6) and nude mice (Table 4).

\section{Immunostaining after Enzymatic Treatment of Tissue Sections}

The biochemical characterization of the nature of the epitope recognized by PNL2 Mab was performed using neuraminidase digestion before PNL2 immunostaining as previously reported for CNA.42 antibody (35). The CNA.42 Mab, which recognizes a

TABLE 1. Reactivity of PNL2 with Normal Human Tissue on Paraffin-Embedded Sections

\begin{tabular}{|c|c|}
\hline Normal Tissue & PNL2 (positive/tested) \\
\hline Adrenal gland & $0 / 4$ \\
\hline Appendix & $0 / 2$ \\
\hline Bladder & $0 / 2$ \\
\hline Bone marrow & $0 / 4$ \\
\hline Breast & $0 / 5$ \\
\hline Central nervous system & $0 / 2$ \\
\hline Cerebellum & $0 / 1$ \\
\hline Colon & $0 / 8$ \\
\hline Duodenum & $0 / 1$ \\
\hline Esophagus & $0 / 3$ \\
\hline Gallbladder & $0 / 2$ \\
\hline Heart & $0 / 4$ \\
\hline Kidney & $0 / 8$ \\
\hline Liver & $0 / 6$ \\
\hline Lung & $0 / 5$ \\
\hline Lymph node & $0 / 5$ \\
\hline Oral mucosa & $4 / 4^{\mathrm{a} \$}$ \\
\hline Ovary & $0 / 2$ \\
\hline Pancreas & $0 / 3$ \\
\hline Peripheral nerves & $0 / 3$ \\
\hline Placenta & $0 / 2$ \\
\hline Prostate & $0 / 4$ \\
\hline Rectum & $0 / 1$ \\
\hline Salivary gland & $0 / 4$ \\
\hline Seminal vesicle & $0 / 2$ \\
\hline Skin & $8 / 8^{a}$ \\
\hline Spleen & $0 / 9$ \\
\hline Stomach & $0 / 4$ \\
\hline Testis & $0 / 4$ \\
\hline Thymus & $0 / 6$ \\
\hline Thyroid & $0 / 8$ \\
\hline Tonsil & $0 / 2$ \\
\hline Uterine cervix & $0 / 2$ \\
\hline Uterus & $0 / 5$ \\
\hline Total & $12 / 135$ \\
\hline
\end{tabular}

"Strong immunostaining restricted to melanocytes.

$\$$ After formalin fixation, nitric acid-based decalcification was performed in two cases.

The immunostaining of the leukocytes was not taken into account. 


\begin{tabular}{|c|c|c|c|}
\hline Tumor Type & $\begin{array}{c}\text { PNL2 } \\
\text { (positive/tested) }\end{array}$ & $\begin{array}{c}\text { HMB-45 } \\
\text { (positive/tested) }\end{array}$ & $\begin{array}{c}\text { Anti Melan A } \\
\text { (positive/tested) }\end{array}$ \\
\hline \multicolumn{4}{|l|}{ Benign lesions } \\
\hline \multicolumn{4}{|l|}{ Nevi } \\
\hline Dermal & $9 / 9^{*}$ & $8 / 9^{*}$ & $9 / 9$ \\
\hline Junctional & $1 / 1$ & $1 / 1$ & $1 / 1$ \\
\hline Compound & $9 / 9^{*}$ & $9 / 9^{*}$ & $9 / 9$ \\
\hline Congenital & $1 / 1^{*}$ & $1 / 1^{*}$ & $1 / 1$ \\
\hline Spitz & $3 / 3^{*}$ & $3 / 3^{*}$ & $3 / 3$ \\
\hline Desmoplastic & $1 / 4$ & $1 / 4$ & $1 / 4$ \\
\hline Pigmented spindle cells (Reed) & $3 / 3$ & $3 / 3$ & $3 / 3$ \\
\hline Common blue & $4 / 4$ & $4 / 4$ & $4 / 4$ \\
\hline Lymph node capsular nevi & $4 / 4^{\phi}$ & $1 / 4^{\phi}$ & $4 / 4^{\phi}$ \\
\hline Dysplastic & $1 / 1$ & $0 / 1$ & $1 / 1$ \\
\hline Lentigo simplex & $8 / 8$ & $8 / 8$ & $8 / 8$ \\
\hline Total & $44 / 47$ & $39 / 47$ & $44 / 47$ \\
\hline \multicolumn{4}{|l|}{ Malignant lesions } \\
\hline \multicolumn{4}{|l|}{ Melanomas } \\
\hline \multicolumn{4}{|l|}{ Primary } \\
\hline Lentigo maligna & $7 / 7$ & $7 / 7$ & $7 / 7$ \\
\hline Superficial spreading & $8 / 8$ & $8 / 8$ & $8 / 8$ \\
\hline Acral lentiginous & $8 / 8$ & $8 / 8$ & $8 / 8$ \\
\hline Nodular & $4 / 4$ & $3 / 4$ & $3 / 4$ \\
\hline In congenital melanocytic nevus & $1 / 1$ & $1 / 1$ & $1 / 1$ \\
\hline Mucosal & $1 / 1$ & $1 / 1$ & nd \\
\hline Desmoplastic & $0 / 3$ & $0 / 3$ & $0 / 3$ \\
\hline \multicolumn{4}{|l|}{ Metastatic } \\
\hline Skin & $10 / 10$ & $9 / 10$ & $9 / 10$ \\
\hline Lymph node & $6 / 6$ & $6 / 6$ & $6 / 6$ \\
\hline Pleural effusion & $1 / 1$ & $1 / 1$ & $1 / 1$ \\
\hline Total & $46 / 49$ & $44 / 49$ & $43 / 48$ \\
\hline Total & $90 / 96$ & $83 / 96$ & $87 / 95$ \\
\hline
\end{tabular}

* Intradermal nevi and dermal component of compound nevi were largely non-reactive and only scattered nevic cells in the papillary dermis are labeled with HMB-45 and PNL2.

$\phi$ PNL2 immunostaining of nodal capsular nevi was weak while the anti Melan A staining was strong and HMB-45 negative or very weak.

nd $=$ not done.

The immunostaining of the leukocytes was not taken into account.

glycosylated epitope expressed by follicular dendritic cells and some mononuclear cells, was used as an internal control for the enzymatic digestion.

\section{Immunoblotting Analysis}

Western blot analysis was performed using the human melanoma derived cell line CAL (our laboratory), the murine melanoma cell line B16F10 and granulocytes obtained from blood samples from healthy volunteer. Negative control consisted of P3 $\times 63$ Ag8-653 cell line. The cell proteins were extracted in lysis buffer (50 mm Tris $\mathrm{HCl} \mathrm{pH} \mathrm{7.5,} 150$ $\mathrm{mm} \mathrm{NaCl}, 1 \%$ Nonidet P40), containing a protease inhibitor mixture (protease inhibitor cocktail Complete, Roche Molecular Biochemical, Mannheim, Germany) and boiled in sample buffer (4\% SDS, 9\% glycerol, $10 \% \quad \beta$-mercaptoethanol/bromophenol blue in $160 \mathrm{~mm}$ Tris $\mathrm{HCl} \mathrm{pH}$ 6.8). Solubilized proteins were resolved through $10 \%$ SDSpolyacrylamide gels, and transferred to PVDF membranes. Blots were incubated with PNL2 supernatant, followed by incubation with horseradish peroxidase conjugated anti-mouse antibody (P0260, Dako). The peroxidase activity was revealed using chemiluminescence reaction (ECL+, Amersham, Little Chalfont, UK).

\section{Immunoprecipitation}

An immunoprecipitation technique was applied to melanoma protein extracts using immunomagnetic beads coated with sheep anti mouse IgG (Dynabeads M-450 sheep anti mouse IgG, Dynal, Oslo, Norway). Briefly, PNL2 supernatant was coated to the beads and was incubated with the protein extracts for 2 hours at $4^{\circ} \mathrm{C}$. After washing, the beads were reduced in loading buffer and resolved through $10 \%$ SDS-PAGE.

\section{Protein Identification by Proteomic Analysis and Mass Spectrometry}

The immunoprecipitates were analyzed using one dimensional electrophoresis and visualized by coomassie blue staining. Peptide mass fingerprintings were obtained by using a PE Biosystems MALDI-TOF mass spectrometer (Voyager DE STR, Foster City, CA, USA) from each protein band (36). Unknown proteins were identified using the database fitting program MS-Fit (Protein Prospector, 
(http://prospector.ucsf.edu)), searching against all eukaryotic entries in Swiss Prot and NCBI nonredundant protein data bases. We considered the identification positive when a minimum of four measured peptide masses was matched and provided at least approximately $20 \%$ sequence coverage (mass accuracy of $10 \mathrm{ppm}$ was obtained with internal calibration).

TABLE 3. Reactivity of PNL2 with Human NonMelanocytic Tumors on Paraffin-Embedded Sections

\begin{tabular}{|c|c|}
\hline Tumor Type & PNL2 (positive/tested) \\
\hline \multicolumn{2}{|l|}{ Haematopoietic neoplasms } \\
\hline Non-Hodgkin's lymphoma & $0 / 57$ \\
\hline Hodgkin's lymphoma of various types & $0 / 15$ \\
\hline \multicolumn{2}{|l|}{ Carcinomas } \\
\hline \multicolumn{2}{|l|}{ Skin } \\
\hline Squamous cell & $0 / 3^{a}$ \\
\hline Basal cell & $0 / 4^{a}$ \\
\hline \multicolumn{2}{|l|}{ Lung } \\
\hline Squamous cell & $0 / 8$ \\
\hline Adenocarcinoma & $0 / 6$ \\
\hline \multicolumn{2}{|l|}{ Gastrointestinal tract } \\
\hline Esophagus (of various types) & $0 / 7$ \\
\hline Stomach & $0 / 5$ \\
\hline Small intestine & $0 / 2$ \\
\hline Large intestine & $0 / 11$ \\
\hline Breast (of various types) & $0 / 7$ \\
\hline Endometrial adenocarcinoma & $0 / 1$ \\
\hline Pancreas adenocarcinoma & $0 / 1$ \\
\hline Liver & $0 / 3$ \\
\hline Prostate adenocarcinoma & $0 / 3$ \\
\hline Kidney & $0 / 2$ \\
\hline Bladder & $0 / 1$ \\
\hline \multicolumn{2}{|l|}{ Thyroid } \\
\hline Papillary carcinoma & $0 / 3$ \\
\hline Follicular carcinoma & $0 / 2$ \\
\hline Medullary carcinoma & $0 / 1$ \\
\hline Adrenal cortical & $0 / 2$ \\
\hline Neuro endocrine tumors of various types & $0 / 10$ \\
\hline \multicolumn{2}{|l|}{ Others } \\
\hline Angiosarcoma & $0 / 1$ \\
\hline Clear cell sarcoma & $6 / 6$ \\
\hline Desmoplastic small cell tumour & $0 / 1$ \\
\hline Ewing sarcoma & $0 / 1$ \\
\hline Fibrous histiocytoma (cellular) & $0 / 1$ \\
\hline Ganglioneuroblastoma & $0 / 1$ \\
\hline Ganglioneuroma & $0 / 1$ \\
\hline Gastrointestinal stromal tumour & $0 / 1$ \\
\hline Glioblastoma & $0 / 5$ \\
\hline Granular cell tumor & $0 / 2$ \\
\hline Keratoacanthoma & $0 / 1$ \\
\hline Leiomyoma & $0 / 2$ \\
\hline Leiomyosarcoma & $0 / 1$ \\
\hline Lipoma (spindle cell type) & $0 / 1$ \\
\hline Liposarcoma & $0 / 1$ \\
\hline Lymphangioleimyomatosis & $3 / 3$ \\
\hline Malignant peripheral nerve sheath tumor & $0 / 2$ \\
\hline Nephroblastoma & $0 / 4$ \\
\hline Neuroblastoma & $0 / 1$ \\
\hline Pheochromocytoma & $0 / 3$ \\
\hline Renal angiomyolipoma & $3 / 3$ \\
\hline Renal oncocytoma & $0 / 1$ \\
\hline Rhabdomyosarcoma & $0 / 2$ \\
\hline Schwannoma & $1 / 3^{\varepsilon}$ \\
\hline Synovialosarcoma & $0 / 1$ \\
\hline Thymoma & $0 / 3$ \\
\hline Yolk sac tumor & $0 / 1$ \\
\hline Total & $13 / 208$ \\
\hline
\end{tabular}

${ }^{a}$ Strong immunostaining restricted to non neoplastic melanocytes.

${ }^{\varepsilon}$ The positive case was a melanotic schwannoma.

The immunostaining of the leukocytes was not taken into account.

\section{RESULTS}

\section{PNL2 Hybridoma Selection}

PNL2 supernatant strongly stained the melanocytes and the granulocytes of the tonsil sections on frozen sections but unexpectedly did not recognize the recombinant protein in ELISA test. Despite the negativity of the ELISA test, PNL2 was selected for further analysis because the immunostaining appeared to be of interest and persisted on paraffin sections after microwave heating based antigen retrieval.

Isotype characterization showed PNL2 to belong to an IgG1 class but no light chain was detected. Furthermore, PNL2 supernatant resolution through $10 \%$ SDS-PAGE showed a 54-kDa band corresponding to the IgG1 heavy chain, but no light chain band was detected (Fig. 1). HHF35, an IgG1 $\kappa$ antibody used as positive control, showed as expected two bands of $54 \mathrm{kDa}$ and $30 \mathrm{kDa}$ respectively, corresponding to heavy and light chains.

\section{Immunoreactivity of PNL2 on Paraffin- Embedded Tissue Sections}

PNL2 immunostainings of melanomas were strong with no background staining. When melanin pigment was bleached by $\mathrm{KMnO}_{4}$ /sodium bisulfite treatment (the slides were immersed in $0.25 \%$ $\mathrm{KMnO}_{4}$ for $2 \mathrm{~min}$, washed and immersed in $2 \%$ sodium bisulfite for $2 \mathrm{~min}$ ), or when a nitric acidbased decalcification was performed, the PNL2 staining was not modified, whereas anti-Melan A and HMB-45 stainings were abolished.

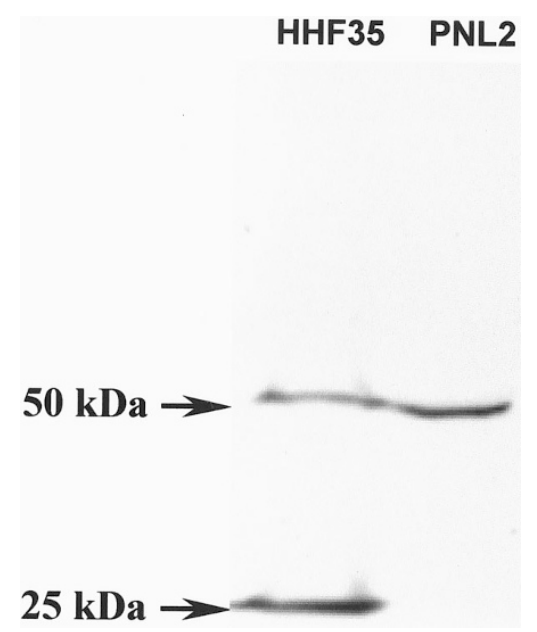

FIGURE 1. SDS-PAGE analysis of PNL2 structure: resolution of PNL2 supernatant and an IgG1 $\kappa$ Mab (HHF35) through 10\% SDS-PAGE. Lane 1: HHF35 antibody is used as positive control: two bands are detected at $54 \mathrm{kDa}$ and $30 \mathrm{kDa}$, corresponding respectively to the IgG1 heavy chain and the $\kappa$ light chain. Lane 2: PNL2 gives only one band at 54 $\mathrm{kDa}$ corresponding to the IgG1 heavy chain but no light chain was detected. 


\section{Human Normal Tissues}

Results of PNL2 immunostainings on human non-neoplastic tissues are summarized in Table 1. PNL2 consistently gave a strong cytoplasmic staining of melanocytes on skin and oral mucosa sections and a moderate staining of granulocytes (Fig. 2). This staining was granular and cytoplasmic and highlighted dendritic prolongements of melanocytes. Except for melanocytes and granulocytes, no other cell was immunostained in the wide variety of normal human tissues tested. When the PNL2 supernatant was diluted, the melanocyte staining remained strong until high dilution were used (i.e., $1 / 50$ ), whereas leukocyte staining disappeared at low supernatant dilution (i.e., 1/10).

\section{Human Melanocytic Tumors}

The staining of PNL2, anti-Melan A, and HMB-45 antibodies on paraffin embedded melanocytic tumors is detailed in Table 2. PNL2 immunostainings were very similar to those obtained with HMB-45. They were always strong with no background staining. About 90 to $100 \%$ of the melanocytes were labeled in all benign intraepidermal lesions, irrespective of their histologic type. As observed with HMB-45, common intradermal nevi and dermal component of compound nevi were largely nonreactive and only scattered nevus cells in the papillary dermis were labeled with PNL2 (Fig. 3), whereas anti-Melan A stained all melanocytes of the benign melanocytic lesions. However, spindleshaped intradermal nevi such as blue nevus and desmoplastic Spitz nevus were consistently and strongly labeled by PNL2.

The PNL2 staining of nodal capsular nevi was weak whereas the anti-Melan A staining was strong, and HMB-45 staining was either negative or very weak.
PNL2 gave a strong immunostaining of 70 to $100 \%$ of the melanocytes in all the non desmoplastic primary melanomas, irrespective of their histologic type (Figure 4). However, PNL2 did not label desmoplastic melanomas. All metastatic melanomas were positively stained by PNL2. The percentage of labeled neoplastic cells varied from case to case from 10 to $100 \%$ (mean, 45\%). However, the staining was always strong, dramatically different from the weak staining of the nodal capsular nevi. The lower percentages of stained cells were most often observed in hypomelanotic lesions. A discrepancy between PNL2, HMB-45, and anti-Melan A staining was observed in two cases: PNL2 gave a strong staining of $10 \%$ of the tumors cells whereas, anti-Melan A and HMB-45 were negative.

\section{Human Non-Melanocytic Tumors}

The staining of PNL2, anti-Melan A, and HMB-45 antibodies on paraffin embedded non melanocytic tumors is detailed in Table 3. PNL2 and anti-Melan A gave a strong immunostaining of most of the neoplastic cells in clear cell sarcomas, of a few cells in angiomyolipomas (Figure 5) and of spindle cells in lymphangioleiomyomatosis. By contrast, HMB-45 immunostaining was strong in clear cell sarcomas but weak in angiomyolipomas and weak or negative in lymphangioleiomyomatosis. One case of melanotic schwannoma was strongly labeled by the three antibodies. None of the other tumors tested were found to be positive for PNL2.

\section{Mouse Normal Tissues}

PNL2 strongly stained numerous melanocytes in the hair bulb of the $\mathrm{C} 57 / \mathrm{Bl} 6$ and nude mice whereas the staining was moderate in Balb/c mice. Furthermore, it gave a moderate immunostaining of the

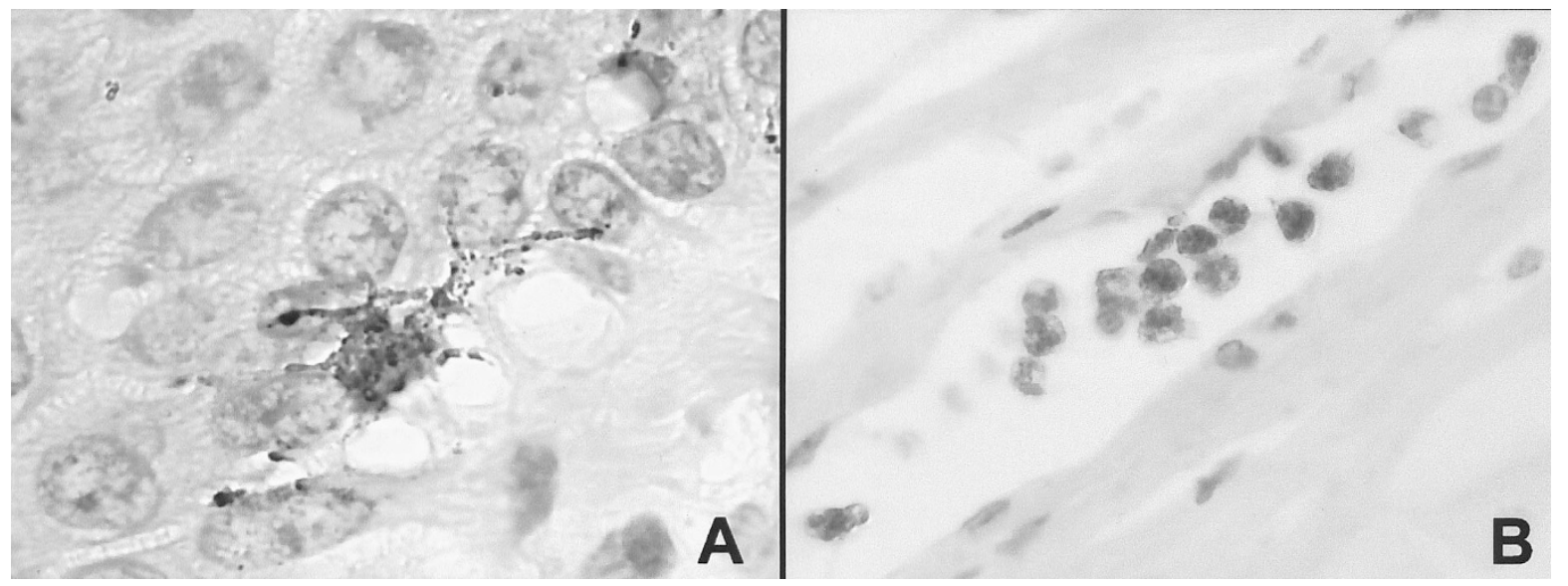

FIGURE 2. PNL2 immunostaining of normal tissues is limited to melanocytes (A) and leukocytes (B): the staining of the skin melanocytes (A) is cytoplasmic and dendritic in a granular pattern. It remained strong up to a supernatant dilution of $1 / 50$. The staining of leukocytes (B) is also cytoplasmic in a granular pattern but it rapidly disappears at low supernatant dilution (i.e., 1/10). 


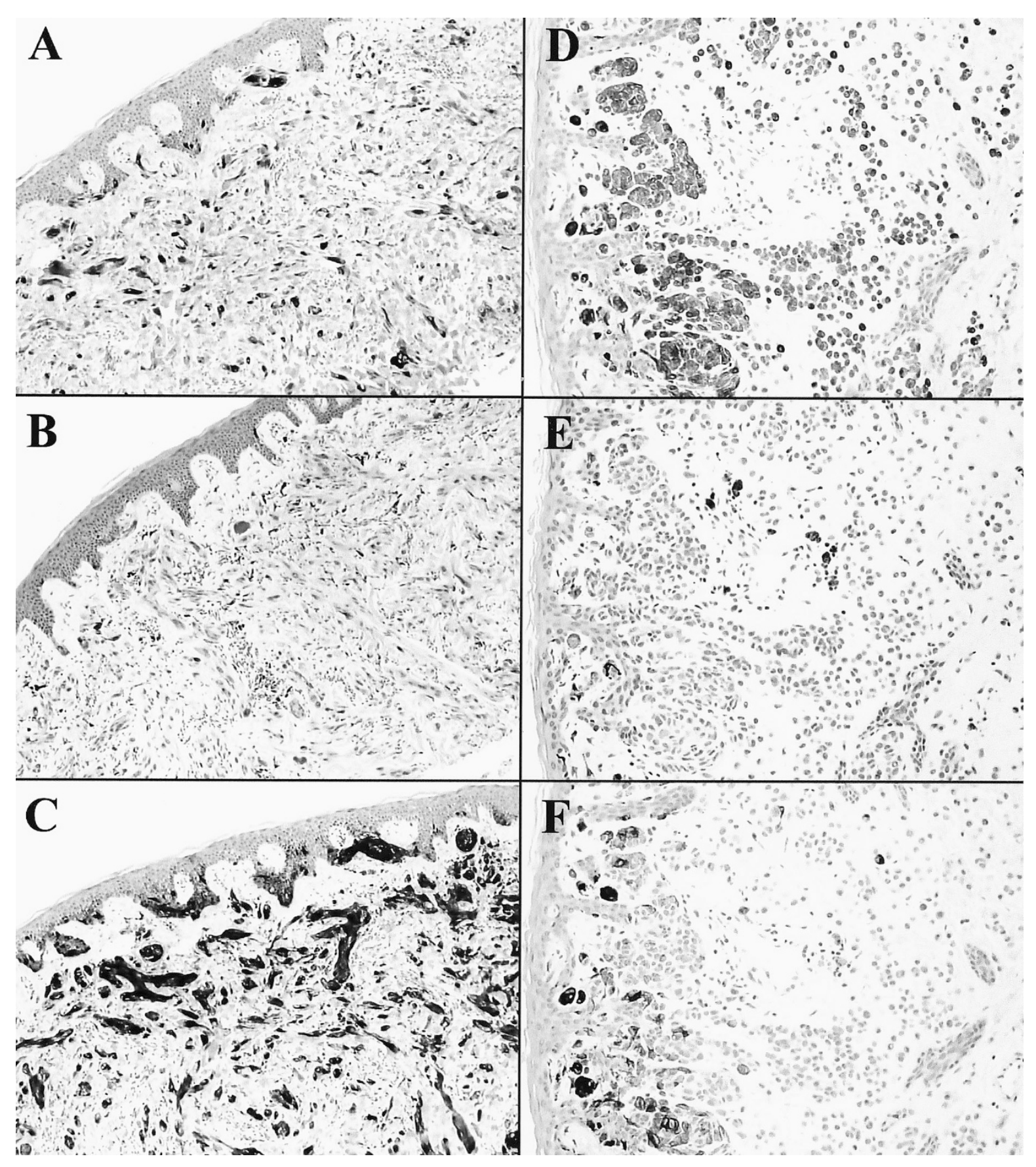

FIGURE 3. PNL2 immunostaining of benign melanocytic lesions, comparison with anti-Melan A and HMB-45 immunostaining. Left side: adjacent sections from a Spitz nevus. Whereas Melan A (A) and HMB-45 (B) stainings are heterogeneous, PNL2 (C) strongly stains all the cells of the nevus. Right side: adjacent sections from a compound nevus. Melan A is expressed by all the nevi cells (D), whereas the intradermal component of this nevus is largely non painted by HMB-45 (E), and PNL2 (F), with only scattered nevus cells labeled in the papillary dermis.

granular cell layer of the cornified esophagus epithelium. Such a staining was observed in all mice studied.

\section{Immunostaining after Enzymatic Treatment of} Tissue Sections

The neuraminidase digestion of sections from lymph node metastatic melanoma before immunostaining had no influence on the PNL2 reactivity but abolished, as expected, CNA.42 staining, sug- gesting that PNL2 did not recognize a glycosylated epitope.

\section{Immunoblotting Analysis}

PNL2 produced three bands with an apparent molecular weight of $160 \mathrm{kDa}, 100 \mathrm{kDa}$, and less than $10 \mathrm{kDa}$ in CAL melanoma cell line, whereas it produced three bands with an apparent molecular weight of $80 \mathrm{kDa}, 70 \mathrm{kDa}$, and less than $10 \mathrm{kDa}$ in B16F10 cell line. 


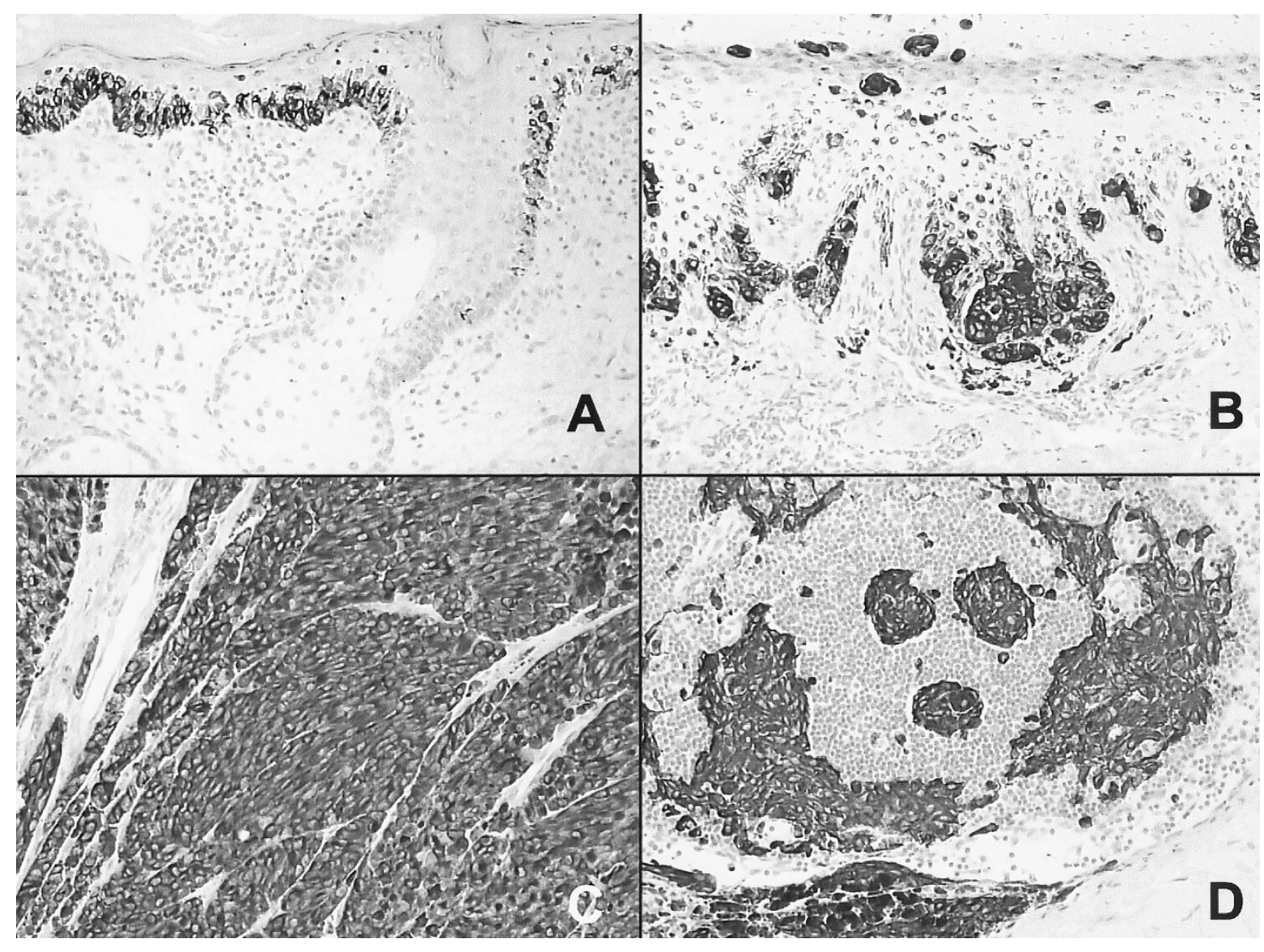

FIGURE 4. PNL2 immunostaining of malignant melanocytic lesions: strong immunostaining of the melanocytes in a lentigo maligna melanoma (A), an acral lentiginous melanoma (B), a nodular melanoma (C), and an achromic melanoma metastasis in a lymph node (D).

A protein with an apparent molecular weight of less than $10 \mathrm{kDa}$ was also detected with the PNL2 Mab in leukocyte protein extracts. No band was observed in P3 $\times 63$ Ag8-653 myeloma cell line used as negative control.

\section{Protein Identification by Proteomic Analysis and Mass Spectrometry}

In human melanoma, identification of the immunoaffinity purified PNL2-binding complexes showed that the $160 \mathrm{kDa}$ protein was the clathrin 17 and that the $100 \mathrm{kDa}$ protein was the vesicular docking protein TAP1. In the B16F10 cell line, the $70 \mathrm{kDa}$ protein was identified as an albumin precursor. The identification of the low molecular weight molecule was not possible in both human and murin melanomas.

\section{DISCUSSION}

PNL2 is a new and interesting anti-melanocyte antibody suitable for use on paraffin sections. On human samples, PNL2 stains only melanocytic lesions, clear cell sarcoma, melanotic schwannoma, angiomyolipoma, and lymphangioleiomyomatosis.
Overall, PNL2 has the same specificity that antiMelan A and HMB-45 antibodies. However, we noted that PNL2 staining is stronger and more consistent than that of HMB-45 antibody. Indeed, occasional melanomas (two in the present study) negative for HMB-45 were found to be strongly positive for PNL2. Staining of non-melanocytic lesions such as lymphangioleiomyomatosis or angiomyolipomas is also stronger than with HMB-45 antibody which often shows a weak and focal staining. In addition, PNL2 staining is not altered by $\mathrm{KMnO} 4 /$ sodium bisulfite melanin bleaching or by a nitric acidbased decalcification. These points are of interest in lesions rich in highly pigmented macrophages or for the immunodetection of bone metastasis. The staining of leukocytes does not cause a diagnostic problem and constitutes a good intrinsic positive control of the immunostaining quality.

The exact nature of the antigen recognized by PNL2 remains to be defined. Even if the staining obtained with PNL2 is very similar to that obtained with HMB-45, the protein recognized is not the gp100. Mass spectrometry analysis identified the clathrin 17 and TAP1 in the PNL2-binding complexes purified by immunoaffinity. However, these 


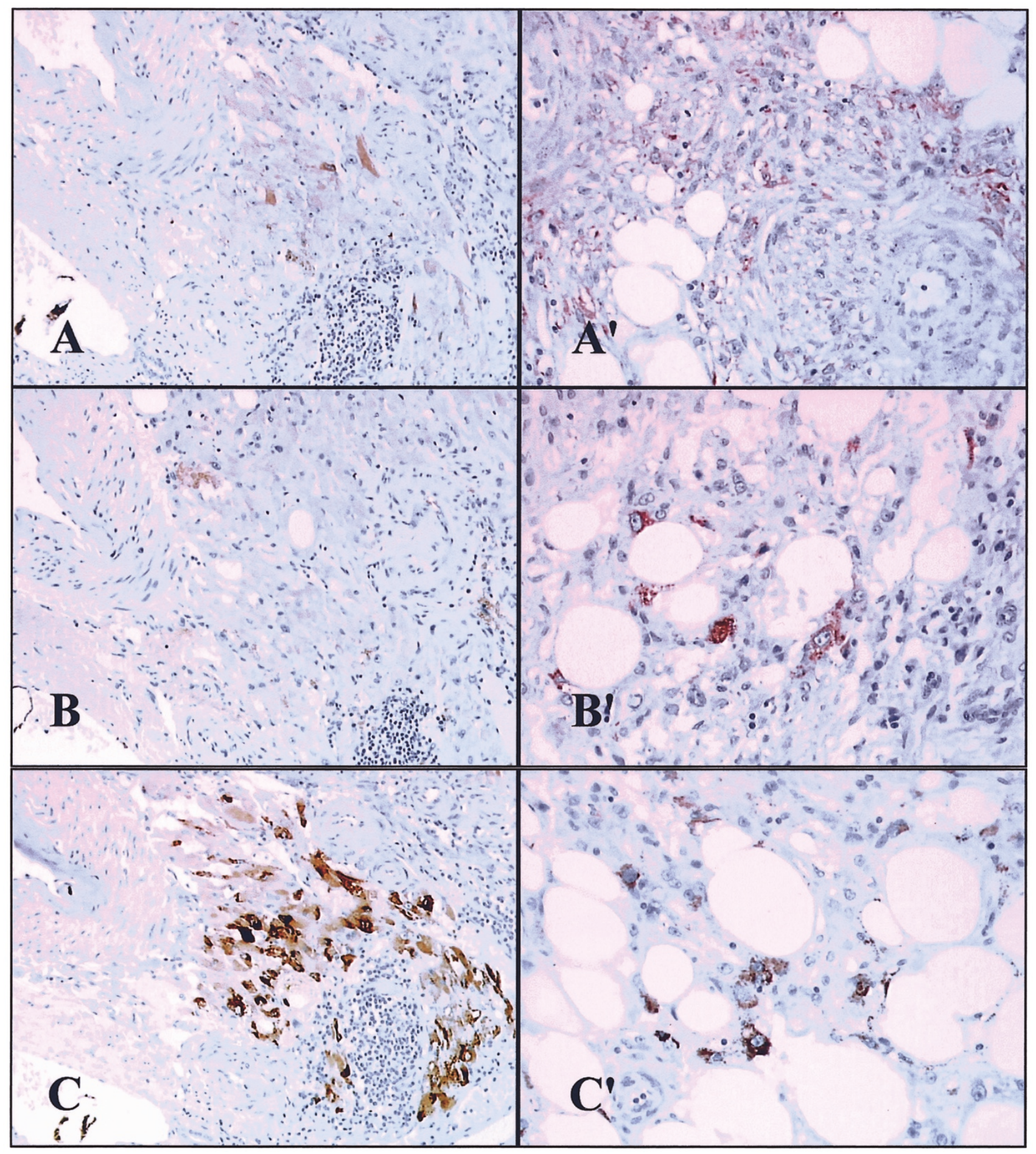

FIGURE 5. PNL2 immunostaining of angiomyolipoma, comparison with anti-Melan A and HMB-45 immunostainings. Adjacent sections from an angiomyolipoma. HMB-45 (A and $\mathbf{A}^{\prime}$ ), anti-Melan A (B and $\left.\mathbf{B}^{\prime}\right)$, and PNL2 (C and $\mathbf{C}^{\prime}$ ) stain the same tumor cells, but PNL2 staining is stronger and more intense.

proteins are probably not the antigens recognized by PNL2. Indeed the clathrin 17 is present in most cells and TAP1 has been reported in numerous cell types, not labeled by PNL2, such as keratinocytes, lymphocytes, breast epithelial cells and trophoblastic cells (37-41). One can hypothesize that the 100$\mathrm{kDa}$ protein immunoprecipitated by PNL2 is not
TAP1 but a melanocytic-related TAP variant because a TAP1 variant has been recently described in rabbit retina, a melanin rich organ (Database references EMBL BC016069; swissprot Q91WE7). It is also possible that the antigen recognized by PNL2 has the same molecular weight that TAP1 or the Clathrin 17 and is masked by these abundant pro- 
teins. Indeed, the proteomic analysis was performed on $1 \mathrm{D}$ gel electrophoresis, and it is well known that more than one protein can be present in a single band with this resolution technique. Finally, we cannot exclude that the very low molecular weight molecule detected by immunoblotting is not a degradation product but the antigen recognized by PNL2. Further studies are needed to identify this low molecular weight product.

The lack of reactivity of PNL2 antibody with the SST2 recombinant protein used as immunogen suggests that splenocytes secreting such an antibody were not immunized B cells, but B cells secreting an auto-antibody directed against a murine associated-melanocyte antigen. The immunostaining obtained in mouse skin supports this hypothesis because PNL2 recognizes Balb/c mouse melanocytes. The negativity of ELISA analysis but the detection of PNL2 antibody in the supernatants emphasizes the value of immunohistochemistry as a primary screening method for hybridoma supernatants (42) because it allows the detection of unexpected but interesting antibodies.

In conclusion, we report here the production of a new monoclonal antibody, PNL2, directed against a new fixative-resistant melanocyte-associated antigen. This antigen which is expressed by human and mouse melanocytes remains to be characterized but we demonstrate that it is different from those recognized by anti-Melan A and HMB- 45 .

\section{REFERENCES}

1. Lodding P, Kindblom LG, Angervall L. Metastases of malignant melanoma simulating soft tissue sarcoma. A clinicopathological, light- and electron microscopic and immunohistochemical study of 21 cases. Virchows Arch A Pathol Anat Histopathol 1990;417:377-88.

2. Fetsch PA, Fetsch JF, Marincola FM, Travis W, Batts KP, Abati A. Comparison of melanoma antigen recognized by $\mathrm{T}$ cells (MART-1) to HMB-45: additional evidence to support a common lineage for angiomyolipoma, lymphangiomyomatosis, and clear cell sugar tumor. Mod Pathol 1998;11:699-703.

3. Adema GJ, Bakker AB, de Boer AJ, Hohenstein P, Figdor CG. pMel17 is recognised by monoclonal antibodies NKI-beteb, HMB-45 and HMB-50 and by anti-melanoma CTL. Br J Cancer 1996;73:1044-8.

4. Adema GJ, de Boer AJ, van't Hullenaar R, Denijn M, Ruiter DJ, Vogel AM, et al. Melanocyte lineage-specific antigens recognized by monoclonal antibodies NKI-beteb, HMB-50, and HMB-45 are encoded by a single cDNA. Am J Pathol 1993;143:1579-85.

5. Busam KJ, Chen YT, Old LJ, Stockert E, Iversen K, Coplan KA, et al. Expression of melan-A (MART1) in benign melanocytic nevi and primary cutaneous malignant melanoma. Am J Surg Pathol 1998;22:976-82.

6. Busam KJ, Iversen K, Berwick M, Spagnoli GC, Old LJ, Jungbluth AA. Immunoreactivity with the anti-MAGE antibody 57B in malignant melanoma: frequency of expression and correlation with prognostic parameters. Mod Pathol 2000;13: 459-65.

7. Busam KJ, Iversen K, Coplan KA, Old LJ, Stockert E, Chen YT, et al. Immunoreactivity for A103, an antibody to melan-A
(Mart-1), in adrenocortical and other steroid tumors. Am J Surg Pathol 1998;22:57-63.

8. Cohen-Knafo E, al Saati T, Aziza J, Ralfkiaer E, Selves J, Gorguet B, et al. Production and characterisation of an antimelanoma monoclonal antibody KBA.62 using a new melanoma cell line reactive on paraffin wax embedded sections. J Clin Pathol 1995;48:826-31.

9. Fetsch PA, Cormier J, Hijazi YM. Immunocytochemical detection of MART-1 in fresh and paraffin-embedded malignant melanomas. J Immunother 1997;20:60-4.

10. Fetsch PA, Marincola FM, Abati A. The new melanoma markers: MART-1 and Melan-A. Am J Surg Pathol 1999;23: 607-10.

11. Gudat F, Zuber M, Durmuller U, Kocher T, Schaefer C, Noppen C, et al. The tumour-associated antigen MAGE-1 is detectable in formalin-fixed paraffin sections of malignant melanoma. Virchows Arch 1996;429:77-81.

12. Hofbauer GF, Kamarashev J, Geertsen R, Boni R, Dummer R. Melan A/MART-1 immunoreactivity in formalin-fixed paraffin-embedded primary and metastatic melanoma: frequency and distribution. Melanoma Res 1998;8:337-43.

13. Hofbauer GF, Schaefer C, Noppen C, Boni R, Kamarashev J, Nestle FO, et al. MAGE-3 immunoreactivity in formalinfixed, paraffin-embedded primary and metastatic melanoma: frequency and distribution. Am J Pathol 1997;151:154953.

14. Jungbluth AA, Busam KJ, Gerald WL, Stockert E, Coplan KA, Iversen K, et al. A103: An anti-melan-a monoclonal antibody for the detection of malignant melanoma in paraffinembedded tissues. Am J Surg Pathol 1998;22:595-602.

15. Kaufmann O, Koch S, Burghardt J, Audring H, Dietel M. Tyrosinase, melan-A, and KBA62 as markers for the immunohistochemical identification of metastatic amelanotic melanomas on paraffin sections. Mod Pathol 1998;11:740-6.

16. Lazzaro B, Strassburg A. Tumor antigen expression in compound dysplastic nevi and superficial spreading melanoma defined by a panel of nevomelanoma monoclonal antibodies. Hybridoma 1996;15:141-6.

17. Ostmeier H, Fuchs B, Otto F, Mawick R, Lippold A, Krieg V, et al. Can immunohistochemical markers and mitotic rate improve prognostic precision in patients with primary melanoma? Cancer 1999;85:2391-9.

18. Biesterfeld S, Kusche M, Viereck E, Fuzesi L. Limited value of the NKI/C3-antibody for the differential diagnosis of Paget's disease of the nipple and intra-epidermal malignant melanoma. Histopathology 1996;28:269-70.

19. Pernick NL, DaSilva M, Gangi M.D., Crissman J, Adsay V. "Histiocytic markers" in melanoma. Mod Pathol 1999;12: 1072-7.

20. Brinckerhoff LH, Thompson LW, Slingluff CL Jr. Melanoma vaccines. Curr Opin Oncol 2000;12:163-73.

21. Mackensen A, Herbst B, Chen JL, Kohler G, Noppen C, Herr $\mathrm{W}$, et al. Phase I study in melanoma patients of a vaccine with peptide-pulsed dendritic cells generated in vitro from CD34(+) hematopoietic progenitor cells. Int J Cancer 2000 1;86:385-92.

22. Mitchell MS. Cancer vaccines, a critical review—Part I. Curr Opin Investig Drugs 2002;3:140-9.

23. Mitchell MS. Cancer vaccines, a critical review-Part II. Curr Opin Investig Drugs 2002;3:150-8.

24. Parmiani G, Castelli C, Dalerba P, Mortarini R, Rivoltini L, Marincola FM, et al. Cancer immunotherapy with peptidebased vaccines: what have we achieved? Where are we going? J Natl Cancer Inst 2002;94:805-18.

25. Ribas A, Butterfield LH, Hu B, Dissette VB, Chen AY, Koh A, et al. Generation of T-cell immunity to a murine melanoma using MART-1-engineered dendritic cells. J Immunother 2000;23:59-66. 
26. Scheibenbogen C, Schmittel A, Keilholz U, Allgauer T, Hofmann U, Max R, et al. Phase 2 trial of vaccination with tyrosinase peptides and granulocyte-macrophage colonystimulating factor in patients with metastatic melanoma. J Immunother 2000;23:275-81.

27. Sun Y, Paschen A, Schadendorf D. Cell-based vaccination against melanoma-background, preliminary results, and perspective. J Mol Med 1999;77:593-608.

28. Thurner B, Haendle I, Roder C, Dieckmann D, Keikavoussi P, Jonuleit $\mathrm{H}$, et al. Vaccination with MAGE-3A1 peptidepulsed mature, monocyte-derived dendritic cells expands specific cytotoxic $\mathrm{T}$ cells and induces regression of some metastases in advanced stage IV melanoma. J Exp Med 1999 6;190:1669-78.

29. Valmori D, Levy F, Miconnet I, Zajac P, Spagnoli GC, Rimoldi $\mathrm{D}$, et al. Induction of potent antitumor CTL responses by recombinant vaccinia encoding a melan-A peptide analogue. J Immunol 2000 15;164:1125-31.

30. Wan Y, Emtage P, Zhu Q, Foley R, Pilon A, Roberts B, et al. Enhanced immune response to the melanoma antigen gp100 using recombinant adenovirus-transduced dendritic cells. Cell Immunol 1999 15;198:131-8.

31. Wang F, Bade E, Kuniyoshi C, Spears L, Jeffery G, Marty V, et al. Phase I trial of a MART-1 peptide vaccine with incomplete Freund's adjuvant for resected high-risk melanoma. Clin Cancer Res 1999;5:2756-65.

32. Weber JS, Hua FL, Spears L, Marty V, Kuniyoshi C, Celis E. A phase I trial of an HLA-A1 restricted MAGE-3 epitope peptide with incomplete Freund's adjuvant in patients with resected high-risk melanoma. J Immunother 1999;22:43140.

33. al Saati T, Clamens S, Cohen-Knafo E, Faye JC, Prats H, Coindre JM, et al. Production of monoclonal antibodies to human estrogen-receptor protein (ER) using recombinant ER (RER). Int J Cancer 1993 21;55:651-4.
34. Harlow E, Lane D. Antibodies: a laboratory manual. New York: Cold Spring Harbor Laboratory; 1988.

35. Raymond I, Al Saati T, Tkaczuk J, Chittal S, Delsol G. CNA.42, a new monoclonal antibody directed against a fixativeresistant antigen of follicular dendritic reticulum cells. Am J Pathol 1997;151:1577-85.

36. Mann M, Hendrickson R, Pandey A. Analysis of proteins and proteomes by mass spectrometry. Annu Rev Biochem 2001; 70:437-73.

37. Clover LM, Sargent IL, Townsend A, Tampe R, Redman CW. Expression of TAP1 by human trophoblast. Eur J Immunol 1995;25:543-53.

38. Clover LM, Coghill E, Redman CW, Sargent IL. A threecolour flow cytometry technique for measuring trophoblast intracellular antigens: the relative expression of TAP1 in human cytotrophoblast and decidual cells. Placenta 2000;21: 743-53.

39. Kishore R, Hicklin DJ, Dellaratta DV, Golde U, Kageshita T, Seliger B, et al. Development and characterization of mouse anti-human LMP2, LMP7, TAP1 and TAP2 monoclonal antibodies. Tissue Antigens 1998;51:129-40.

40. Matsui M, Ikeda M, Akatsuka T. High expression of HLA-A2 on an oral squamous cell carcinoma with down-regulated transporter for antigen presentation. Biochem Biophys Res Commun 2001;280:1008-14.

41. Palmisano GL, Pistillo MP, Capanni P, Pera C, Nicolo G, Salvi $\mathrm{S}$, et al. Investigation of HLA class I downregulation in breast cancer by RT-PCR. Hum Immunol 2001;62:133-9.

42. al Saati T, Caspar S, Brousset P, Chittal S, Caveriviere P, Hounieu $\mathrm{H}$, et al. Production of anti-B monoclonal antibodies (DBB.42, DBA.44, DNA.7, and DND.53) reactive on paraffin-embedded tissues with a new B-lymphoma cell line grafted into athymic nude mice. Blood 1989;74:247685. 